\title{
Suggestions on improving the financial management system of public institutions
}

\author{
Pei Wenjun \\ Yunnan science and technology museum
}

Key words: public institution; financial management system; suggestion; development level

\begin{abstract}
Under the new situation, the gradual improvement of the development level of institutions puts forward higher requirements for the effective development of financial management related to it. In this context, in order to maintain the good financial management of institutions, and enhance the implementation effect of their financial management in practice, it is necessary to improve their financial management system for in-depth thinking, put forward relevant suggestions to deal with. Based on this, this paper discusses several suggestions to improve the financial management system of institutions, in order to provide effective guarantee for the enhancement of its financial management effect.
\end{abstract}

\section{完善事业单位财务管理体系的几点建议框架思路构建}

\author{
裴文君 \\ 云南省科学技术馆
}

关键词: 事业单位; 财务管理体系; 建议; 发展水平

摘要: 新形势下事业单位发展水平的逐渐提升, 对与之相关的财务管理工作有效开展提出了更高要求。在 此背景下, 为了保持事业单位良好的财务管理状况, 增强其财务管理工作在实践中的落实效果, 则需要对 完善其财务管理体系进行深入思考, 提出相关的建议予以应对。基于此, 本文就完善事业单位财务管理体 系的几点建议展开论述，以便为其财务管理效果的增强提供有效保障。

\section{1. 引言}

通过对构建事业单位财务管理体系的几点建议框架思路构建分析，可为相应的财务管理 工作开展提供科学指导, 促使事业单位在长期实践中的财务管理状况得以改善, 最大限度地 降低其财务问题发生率。因此, 需要对事业单位财务管理体系不断完善, 提出有效的建议对 该体系加以完善, 使得事业单位在实践中的财务管理体系开展更具针对性, 从而实现对其生 产实践中可能发生财务风险的有效应对。

\section{2. 完善事业单位财务管理体系的必要性分析}

为了使事业单位财务管理体系在长期的实践中可逐渐完善, 则需要对其完善的必要性有 所了解。具体表现为:（1）完善事业单位财务管理体系, 有利于实现对国有资产的有效保护 及高效利用, 满足其财务管理工作高效开展要求; (2) 完善事业单位财务管理体系, 有利于 满足与时俱进的发展要求, 并降低事业单位生产实践中的财务风险, 给予其经营活动的顺利 开展可靠保障;（3）完善事业单位财务管理体系, 使使其财务管理方面有着良好的技术含量, 并为事业单位的可持续发展打下坚实的基础，丰富其财务管理方面的实践经验。 


\section{3. 事业单位财务管理的特点及目标分析}

实践中为了提升对事业单位财务管理的认知水平，给予其财务管理体系完善过程相应的 参考信息, 则需要了解其财务管理的特点及目标并加以分析。具体表现在以下方面:

（1）事业单位财务管理的特点。具体的特点包括：财务管理中应坚持公益属性。由于事 业单位是国家为了社会公益而建立的各类机构, 因此, 其财务管理中需要通过对公益属性的 考虑与坚持, 针对性的开展财务方面的管理工作; 通过对实践中形势变化的深入分析, 事业 单位财务管理中应加强经济核算、绩效管理, 最大限度地提高资金利用效率; 事业单位财务 管理中需要确保国有资产安全, 避免其浪费或流失现象的出现。实践中通过对事业单位财务 管理这些特点的综合考虑, 能够使其财务管理开展更具科学性, 满足其生产经营活动开展中 的资源优化配置要求。

（2）事业单位财务管理的目标。其财务管理目标具体包括：优化财政资源配置，确保生 产实践中的预算平衡, 满足自身的可持续发展要求; 真实反映事业单位的财务状况, 节约实 践中的支出, 提高资金利用效率; 实现对国有资产的科学管理, 降低其流失问题发生率, 并 对事业单位经济活动开展过程进行财务监督与控制，实现对其财务风险的有效应对。

\section{4. 完善事业单位财务管理体系的相关建议}

\section{1 加强综合预算管理}

在事业单位财务管理过程中，其预算管理是否有效，与其财务管理工作落实效果是否良 好密切相关。因此, 在完善事业单位财务管理体系的过程中, 需要根据实际情况, 不断加强 其综合预算管理。具体表现为：（1）事业单位及财务管理人员应给予实践中的综合预算管理 更多的重视, 强化预算就是效益的意识, 且在实践中将预算与管理有效地结合起来, 从而增 强事业单位生产实践中的综合预算管理效果, 给予其财务管理体系完善过程中所需的参考信 息; (2) 事业单位应根据实践中的形势变化, 并结合与时俱进的发展要求, 加强财务预算的 约束性控制, 提高其审批约束力, 且财务部门应对各项业务支出的预算执行进度进行严格把 控, 健全预算绩效考评激励机制, 实施好预算绩效层层问责制, 从而增强实践中的综合预算 管理效果。在此基础上，可满足事业单位财务管理体系完善方面的要求。

\section{2 健全资产管理制度}

某些事业单位实践中由于存在着基础工作不扎实、资产优化配置管理制度不完善、资产 管理信息化水平有待提升等问题，使得国有资产利用效率降低，可能会出现这类资产流失现 象的出现。针对这种情况, 在完善事业单位财务管理体系的过程中，应健全其资产管理制度。 具体表现为: (1) 结合事业单位资产管理要求, 将创新理念、管理方面的专业理论知识等融 入到其资产管理制度形成过程中，使得这类制度在事业单位生产实践中得以健全，进而为其 财务管理体系的不断完善提供保障;（3）在健全事业单位资产管理制度的过程中，应对其既 有的资产管理制度实践应用效果进行全面评估，针对性的开展优化处理工作，从而满足事业 单位资产管理中所需制度健全方面的需要, 给予其财务管理体系完善可靠保障, 实现对国有 资产流失问题的有效应对。

\section{3 改善会计核算工作状况, 完善经济责任制}

为了达到事业单位财务管理体系不断完善的目的, 则需要通过对其具体情况的分析, 改 善事业单位会计核算工作状况，完善其经济责任制。具体表现为:（1）细化事业单位会计核 算工作内容，对其会计科目设置是否完整进行充分考虑，且在会计报表的支持下将不同的项 目列举出来, 并通过对有效的会计核算处理方式的积极探索, 从而改善事业单位会计核算工 作状况, 为其财务管理体系的不断完善提供参考依据; (2) 事业单位应在责、权、利相结合 的原则支持下, 明确单位中各部门负责人的职责所在, 且在丰富的实践经验、创新理念等要 
素的配合作用下，完善经济责任制，从而降低自身在经济活动开展中的问题发生率，最终达 到事业单位财务管理水平逐渐提升的目的，满足其财务管理体系完善方面的要求。

\section{4 其它方面的建议}

为了使事业单位财务管理体系更加完善，也需要做到：（1）通过对内部控制制度功能特 性的考虑, 不断完善这类制度予以应对。在此期间, 需要事业单位给予内部控制制度建设更 多的考虑与支持，且在民主决策机制、预决算编制等制度的支持下，对自身的内部控制制度 加以完善，使得其在实践中可发挥出应有的作用，给予财务管理体系完善相应的支持;（2） 为了提高财务信息的透明度, 事业单位在完善财务管理体系的过程中也需要考虑社会监督, 并在实践中对其进行有效接受, 确保自身的财务管理工作状况良好性; (3) 在专业培训活动、 奖惩机制的作用下, 实现对财务管理人才的科学培养, 促使事业单位财务管理工作开展更加 高效，增强其财务管理体系实践应用效果。

\section{5. 提升事业单位财务管理体系实践应用水平的措施分析}

在完善事业单位财务管理体系的基础上，为了使其实践应用水平得以提升，则需要加强 相关的措施使用予以应对。具体的措施包括以下方面:

\section{1 控制好财务管理体系的实践应用过程}

在事业单位财务管理体系实践应用水平提升过程中，为了降低其中的问题发生率，则需 要对其实践应用过程加以控制。具体表现为:（1）通过对事业单位财务管理体系功能特性的 考虑, 针对性的建立并完善与之相关的控制机制, 将这类机制作用于财务管理体系实践应用 过程, 使得事业单位的财务管理工作状况可逐渐改善, 从而提升这类管理体系在事业单位发 展中的应用水平, 给予相应的管理工作有效开展更多的支持;（2）在事业单位财务管理体系 应用过程中, 需要管理人员根据实际情况, 针对性的开展相应的控制工作, 使得这项工作作 用下的财务管理体系实践应用过程可得到有效控制，从而为事业单位的长远发展打下坚实的 基础, 并实现对其财务管理问题的有效应对; (3) 事业单位财务管理人员应强化其管理体系 实践应用过程中的控制意识, 促使相应的控制工作开展更具科学性, 进而为财务管理工作的 高效开展提供保障, 提升事业单位财务管理体系实践应用水平的同时确保其应用效果良好性。

\section{2 给予财务管理体系的科学应用有效支持}

财务管理体系在事业单位实践中的应用水平能否提升，与其应用过程中是否可以得到有 效支持密切相关。因此, 通过对实践中形势变化的深入分析, 在财务管理体系应用过程中, 需要事业单位能够给予其有效支持。具体表现为:（1）全面提升对财务管理体系应用重要性 的认知水平，使得其实践应用方面的相关研究工作开展能够得到有效支持，从而为事业单位 财务管理体系的实践应用水平提升打下基础, 最大限度地降低财务管理工作在事业单位发展 中的问题发生率; (2) 事业单位在财务管理体系应用过程中, 需要给予其更多的支持, 处理 好该管理体系应用过程中的细节问题，从而满足其实践应用水平逐渐提升方面的要求;（3） 当事业单位财务管理体系应用过程中得到有效支持后, 可为相应的管理工作开展提供更多的 指导, 提高这项管理工作效率的同时为其管理方式的持续优化积累丰富的实践经验, 确保事 业单位生产实践中的经济效益不受影响。实践中通过对这些措施的配合使用, 可使事业单位 财务管理体系在长期的实践中逐渐提升, 并保持该管理体系良好的应用价值, 满足事业单位 的可持续发展要求。

\section{3 重视信息技术与计算机网络的配合使用}

为了达到事业单位财务管理体系实践应用水平逐渐提升的目的, 充分发挥其在财务管理 工作开展中的保障作用, 则需要事业单位能够根据信息化时代背景下的发展要求, 重视其财 
务管理体系应用过程中信息技术与计算机网络的配合使用, 进而增强该管理体系应用过程中 的技术含量。具体表现为:（1）基于信息技术与计算机网络的事业单位财务管理体系应用, 能够对可能影响其实践应用效果的因素加以分析, 使得财务管理人员可用针对性强的措施进 行科学处理, 从而为事业单位财务管理体系的实践应用水平提升提供技术支持;（2）在财务 管理体系应用过程中，事业单位若能重视信息技术与计算机网络的配合使用，则能为财务管 理体系应用中提供丰富的信息资源, 给予该管理体系的科学应用更多的支持, 促使财务管理 体系在事业单位生产实践中的应用水平能够提升。

\section{4 不断积累财务管理体系应用方面的实践经验}

事业单位在提升财务管理体系实践应用水平时，应结合与时俱进的发展要求，不断积累 该管理体系应用方面的实践经验予以应对, 确保财务管理体系在自身发展中的应用状况良好 性。具体表现为:（1）通过对财务管理体系在财务工作状况改善方面所发挥作用的充分考虑, 事业单位应在其应用过程中不断积累丰富的实践经验, 使得财务管理体系应用方面的研究工 作开展更具针对性, 满足其应用水平提升要求的同时保持财务管理体系良好的适用性, 确保 事业单位财务活动开展中所涉及的资源可达到优化配置的目的; (2) 当财务管理体系实践应 用方面的经验逐渐丰富后, 可使其应用过程中更好地适应形势变化, 从而为事业单位的更好 发展注入活力, 有效应对其在实践中可能出现的财务问题; (3) 通过对事业单位财务管理体 系应用过程中实践经验的不断积累, 可为该管理体系的研究工作开展提供参考依据, 促使财 务管理体系在事业单位长远发展中的实践应用状况可逐渐改善, 最终达到其应用水平提升的 目的。

\section{5 加强人员方面的素质培养, 强化责任意识}

在了解财务管理体系在事业单位财务管理中所发挥作用的前提条件下，为了确保该管理 体系的实践应用水平可逐渐提升, 也需要事业单位不断加强人员方面的素质培养, 强化他们 的责任意识, 实现对财务管理体系的高效利用。具体表现为:（1）事业单位应加大财务管理 人员的绩效考核力度, 且在责任机制的配合作用下, 实现对这类人员专业能力的科学培养, 并强化他们的责任意识, 使得财务管理体系的应用水平能够持续提升; (2) 事业单位财务管 理人员的整体素质得到有效培养后, 可使他们在财务管理体系应用过程中保持高度的责任感, 从而为这类体系的科学应用提供有效保障, 避免对事业单位的经济效益、社会效益等造成不 利影响。

\section{6. 事业单位财务管理体系应用中的注意事项}

在保持事业单位财务管理体系良好应用效果的过程中, 需要对相关的注意事项有所了解。 具体表现为:（1）做好财务管理体系应用过程中出现问题的分析与总结工作，确保其在事业 单位财务管理活动开展中的实际作用可充分发挥; (2) 注重有效的财务管理机制、财务管理 工作的配合使用, 使得事业单位财务管理体系可以不断完善;（3）在创新理念、与时俱进发 展要求等要素的作用下, 重视事业单位财务管理体系应用过程中控制方式的不断优化, 促使 其实践应用效果更加显著，改善其应用状况。

\section{7. 结束语}

综上所述，在这些建议的支持下，可完善事业单位发展中所需的财务管理体系，从而增 加其财务管理中的技术含量, 满足事业单位的可持续发展要求。因此, 未来在开展事业单位 财务方面的研究工作时, 为了保持其良好的财务管理状况及效果, 为其管理工作高效开展提 供制度保障, 则需要给予其财务管理体系的完善足够的重视, 且在切实有效的建议作用下, 提升该管理体系的潜在应用价值。在此基础上, 可使事业单位在生产实践中的财务工作开展 
更加高效。

\section{Reference}

[1] Yang Yang. Research on strengthening the financial management system of public institutions [J]. China market, 2018 (23): 82-83.

[2] Yang Lu. Under the current situation, the financial management strategy of administrative institutions is studied. [J]. pays taxes, 2018 (23): 87.

[3] ho Po. On the innovation of financial management in public institutions under the new situation [J]. tax payment, 2018 (22): 47-48.

[4] Guan Yin. The meticulous development of financial management in public institutions. [J]. financial economy, 2018 (14): 188-189. 